\title{
A construção discursiva do gosto de classe na telenovela: enunciação e midiatização do consumo de semijoias em Império ${ }^{1}$
}

The discursive construction of social class taste in telenovelas: enunciation and mediatization of jewellery consumption in Império

\author{
Maria Cristina Palma Mungioli2 \\ Rosana Mauro ${ }^{3}$
}

Resumo Com base no conceito de midiatização (COULDRY e HEPP, 2013), o artigo discute aspectos da produção de sentido do gosto de classe por meio da análise do discurso da telenovela Império (Globo, 2014-2015). O estudo baseado na enunciação sobre um "anel de formatura" mostra ao mesmo tempo a oposição entre gosto de luxo e gosto popular como diferença de classe e a produção de sentido de consumo de produtos tangiveis e intangíveis pelas classes populares. A discussão foi baseada em estudos de Bakhtin e Voloshinov (2002), Bourdieu (1983, 2008), Fiorin (1997, 2005, 2008), Maingueneau (2008) e Landowski (1997) e Lipovetsky (2009).

Palavras-chave: Telenovela; gosto; classe social; midiatização; consumo

Abstract Based on the Mediatization concept (COULDRY, HEPP, 2013), the article discusses aspects of meaning production of class taste through speeches analysis from the telenovela Imperio (Globo, 2014). The study based on the enunciation regarding a "class ring" shows both the opposition between luxury and

\footnotetext{
1 Telenovela de Aguinaldo Silva, direção-geral de Rogério Gomes, exibida na Rede Globo no horário das 21 horas entre os dias 21 de julho de 2014 e 13 de março de 2015.

2 Universidade de São Paulo, Escola de Comunicações e Artes - ECA/USP. São Paulo, SP, Brasil. E-mail: crismungioli@usp.br

${ }^{3}$ Universidade de São Paulo, Escola de Comunicações e Artes - ECA/USP. São Paulo, SP, Brasil. E-mail: mauro.rosana@gmail.com
} 
74 A CONSTRUÇÃo DisCURSIVA Do GOSTO DE ClASSE NA TELENOVELA

popular taste as class difference, and the meaning production of consumption of tangible and intangible products by the poplar classes. The discussion has based on studies from Bakhtin and Voloshinov (2002), Bourdieu (1983, 2008), Fiorin (1997, 2005, 2008), Maingueneau (2008) and Landowski (1997) and Lipovetsky (2009).

Keywords: Telenovela; taste; social class; mediatization; consumption 


\section{Introdução}

Este artigo é uma breve análise que se insere no rol dos estudos sobre telenovela e consumo desenvolvidos no Brasil que vêm se caracterizando pela abordagem interdisciplinar de temáticas abrangentes relacionadas ao consumo material e simbólico das/nas ficções televisivas. Vertente que já conta com um grande número de pesquisas que tratam desde o estudo da linguagem teleficcional e suas representações até os desdobramentos materiais e simbólicos integrados às práticas, usos (CERTEAU, 2007) e recepção, passando por questões que se entrecruzam e se complexificam no circuito da comunicação (HALL, 2003).

Neste artigo, discutimos alguns aspectos da produção de sentido do gosto de classe por meio do estudo dos discursos de uma cena da telenovela Império (Globo, 2014-2015). Temos como ponto de partida o conceito de midiatização (COULDRY e HEPP, 2013) e de gosto. O estudo centra-se na enunciação de algumas personagens sobre o objeto "anel de formatura”, o que possibilita observar não apenas a oposição entre gosto de luxo e gosto popular como diferenciadores de classe, mas também os sentidos de inclusão e exclusão do consumo de bens tangíveis e intangíveis pelas classes populares. Além dos autores anteriormente mencionados, constituem-se como referências teóricas principais para este estudo Bourdieu (1983, 2008), Fiorin (1997, 2005), Maingueneau (2008), Landowski (1997) e Lipovetsky (2009).

Embora o foco de nossa análise seja a produção de sentidos do consumo por meio dos discursos veiculados em uma telenovela e se localize naquilo que se convencionou chamar polo da produção, cabe enfatizar a importância das pesquisas de recepção no que tange os estudos de consumo da telenovela brasileira. ${ }^{4}$ Uma vertente desses trabalhos aproxima-se mais dos objetivos deste artigo, já que se caracteriza pela discussão e análise da correlação entre as práticas de consumo material e simbólico como parte integrante da constituição da cidadania na

\footnotetext{
${ }^{4}$ Entre tais pesquisas, destacamos: Vivendo com a telenovela: mediações, recepção, teleficcionalidades (LOPES, BORELLI e RESENDE, 2002); Telenovela nas relações comunicação e consumo: diálogos Brasil e Portugal (TONDATO e BACCEGA, 2013); O tecer das emoções femininas em Vila Pouca do Campo: a telenovela Senhora do Destino (TRANQUILIN-SILVA, 2006).
} 
contemporaneidade permeada pela comunicação (CANCLINI, 2008). Nesse sentido, destacamos, junto com Canclini (2008) e Baccega e Orofino (2013), que, neste artigo, compreende-se o consumo a partir de uma abordagem que situa "as práticas de consumo, enquanto práticas de cultura” BACCEGA e OROFINO, 2013, p. 67). Na conjunção do binômio consumo e cidadania, Tondato (2010) destaca, filiando-se ao pensamento de Canclini (2008), que, na atualidade,

Ser cidadão inclui exercer o direito do consumo simbólico e cultural, definidores do consumo material. É por meio do caráter simbólico do consumo que o indivíduo-sujeito dialoga com a sociedade do seu tempo, informando seus interlocutores a respeito de sua identidade, seus hábitos, posicionando-se no mundo (TONDATO, 2010, p. 6).

Mais especificamente, dedicamo-nos a compreender os sentidos produzidos a partir da enunciação e dos discursos de personagens da telenovela Império sobre os usos sociais e simbólicos de um produto de consumo: um anel de formatura.

Nesse quadro, cabe destacar alguns aspectos de pesquisas que estudaram a relação entre telenovela e consumo de bens materiais e simbólicos. O livro Telenovela, consumo e gênero: "muitas mais coisas" (ALMEIDA, 2003) é de grande importância para as discussões que se delineiam neste artigo. No livro, a autora relata a pesquisa de recepção que realizou, entre moradoras de Montes Claros, Minas Gerais, da telenovela O Rei do Gado (Globo, 1996-1997). Dentre outros resultados, seu trabalho revela a importância da trama para as práticas de consumo material e simbólico das entrevistadas que nela se baseavam para aquisição e uso de roupas, acessórios, móveis e objetos de decoração. De acordo com a autora, a telenovela, além de constituir uma vitrine de produtos, é uma divulgadora de estilos de vida, atuando, nesse sentido, muito mais incisivamente que a publicidade veiculada nos intervalos comerciais, já que os produtos usados na telenovela contam com mais tempo e atenção dos telespectadores.

Outra obra que trata mais diretamente diversas facetas da relação telenovela e consumo de bens materiais e simbólicos, sob o prisma do 
deslocamento das antigas abordagens que colocavam o consumo como decorrentes apenas da "racionalidade econômica" (CANCLINI, 2008, p. 61), é o livro organizado por Orofino e Baccega, Consumindo e vivendo a vida: telenovela, consumo e seus discursos. A obra oferece um amplo panorama de pesquisas que consideram as práticas de consumo, dentre as quais se situa o consumo de telenovela, a partir de uma abordagem que aponta

na direção da politização e da reflexividade de modo anteriormente recusado pelas teorias da sociedade e da cultura, que, mesmo em suas tendências críticas, localizavam o consumidor como sujeito determinado pelas lógicas puramente econômicas, mercantis e de racionalidade instrumental (BACCEGA e OROFINO, 2013, p. 7).

Para Hamburger (1998), entre outros aspectos, as telenovelas difundem por todo o país o universo glamouroso de consumo das classes médias urbanas por meio da aquisição e do uso dos últimos lançamentos de produtos eletrônicos, de decoração e vestuário por parte das personagens das tramas. Tondato (2011), por sua vez, analisa o blog Sonhos de Luciana, da personagem de mesmo nome em Viver a Vida (Globo, 2009-2010), e discute o papel da telenovela em propagar e divulgar novos estilos e modos de vida ao mostrar "[...] práticas cotidianas diferenciadas e inovações tecnológicas, promovendo desejos, ampliando sensibilidades para novas expectativas de consumo" (TONDATO, 2011, p. 12). Em outro texto, enfocando a questão das distinções sociais, Tondato (2012) as analisa por meio do estudo dos estilos de alimentação das famílias da telenovela Fina Estampa (Globo, 2011-2012).

Voltando-nos mais diretamente para o objeto empírico tratado neste artigo, a telenovela Império (Globo, 2014-2015), de Aguinaldo Silva, verificamos que seu principal arco narrativo se constrói em torno da família proprietária da joalheria Império. O comendador José Alfredo Medeiros, patriarca da família, comanda a empresa com a ajuda de seus três filhos e da esposa, com a qual mantém um casamento de aparências. A família costuma se desentender em razão de disputas em torno de dinheiro e poder. A discórdia familiar acirra-se com a chegada de uma 
nova herdeira, Cristina, que será reconhecida pelo comendador como filha e herdeira de sua fortuna. A construção da trama da telenovela em torno da joalheria da família possibilitou ações de merchandising para a marca de semijoias Rommanel, ${ }^{5}$ como trataremos posteriormente.

Isso posto, busca-se neste artigo investigar aspectos dos sentidos de gosto e valor produzidos pela construção discursiva e narrativa em torno das semijoias apresentadas com o objetivo de refletir sobre o processo de midiatização. Para isso, analisaremos discursos sobre os gostos de classe, baseando-nos em alguns trechos específicos da trama, com foco nas personagens Maria Clara (Andrea Horta), filha do comendador José Alfredo de Medeiros (Alexandre Nero) e designer da Império, e Cristina (Leandra Leal), filha ilegítima do comendador que, ao longo da trama, assume a direção da empresa.

\section{Midiatização}

De um modo amplo, “[...] midiatização é um conceito usado para analisar criticamente a inter-relação entre mudanças na mídia e comunicações por um lado, e mudanças na cultura e sociedade, por outro" (COULDRY e HEPP, 2013, p. 197). Tal conceito torna-se importante para a nossa discussão uma vez que a telenovela assume um papel privilegiado na construção de um imaginário social brasileiro, inclusive em relação ao sentido de classes sociais e consumo (LOPES, 2009) de bens tangíveis e intangíveis no Brasil.

Referindo-se ao consumo especificamente, Almeida (2003) afirma que a telenovela pode ser uma vitrine não só de produtos, mas também de estilos de vida associados aos bens. Para a autora, as telenovelas funcionam de modo semelhante aos anúncios publicitários, com a vantagem de ter mais tempo e espaço para trabalhar o universo do consumo, já que não apenas expõe o telespectador/consumidor a uma história de longa duração, mas porque familiariza "o espectador com mundos

\footnotetext{
${ }^{5}$ De acordo com o site da empresa, a Rommanel fabrica joias folheadas a ouro $18 \mathrm{k}$ e ródio e joias em aço. A marca possui lojas em todo o Brasil e conta com o trabalho de revendedores. Disponível em: http://www.rommanel.com.br/. Acesso em: 2 maio 2015.
} 
diversos, vários estilos de vida e concepções que são usadas pela publicidade para promover bens e serviços" (ALMEIDA, 2003, p. 42). Além de demonstrar didaticamente o uso de certos bens, a telenovela permite uma identificação entre o produto e seu usuário ideal. Cabe, entretanto, destacar, com base em Certeau (2007, p. 93), que a relação que se estabelece entre os produtos presentes nas telenovelas e os telespectadores não se resume apenas a um aspecto econômico, mas "como o repertório com o qual os usuários procedem a operações próprias”, indicando que o consumo implica operações mais complexas que desvelam não apenas questões econômicas, mas principalmente sociais e culturais. No mesmo sentido, Bourdieu (2008, p. 95) afirma que "o consumo de bens pressupõe - sem dúvida, sempre e em graus diferentes segundo os bens e os consumidores - um trabalho de apropriação", o qual "contribui para produzir o produto que ele consome mediante um trabalho de identificação e decifração".

Para Canclini (2008, p. 42), a apropriação do consumo se destaca pela participação do consumidor, já que "ao consumir também se pensa, se escolhe e reelabora o sentido social”, e "é preciso se analisar como esta área de apropriação de bens e signos intervém em formas mais ativas de participação do que aquelas que habitualmente recebem o rótulo de consumo".

Sodré (2014, p. 109) afirma que a midiatização é um conceito descritivo "de um processo de mudanças qualitativas em termos de configuração social por efeito da articulação da tecnologia eletrônica com a vida humana". O autor destaca esse conceito "por sustentar a hipótese de uma mutação sociocultural centrada no funcionamento atual das tecnologias da comunicação" (SODRÉ, 2014, p. 109).

Trindade e Perez (2014) discutem a midiatização com base nas dimensões da presença da mídia na formação de hábitos e atitudes de consumo e na construção de vínculos de sentidos entre as expressões da marca/produtos/serviços e seus consumidores. Os estudos do consumo midiatizado "buscam compreender as formas de presença e consequências das atuações do sistema publicitário (via marcas de empresas, 
produtos e serviços)" (TRINDADE e PEREZ, 2014, p. 3). Enfocando mais especificamente o sistema publicitário, os autores afirmam que a comunicação de marcas por meio desse sistema gera práticas e referências culturais de consumo. Desse modo, o ritual de consumo, do ponto de vista comunicacional, é percebido "como dispositivo articulador dos sentidos dos produtos/marcas na vida das pessoas, portanto, a presença do sistema publicitário é constitutiva nesta relação de consumo" (TRINDADE e PEREZ, 2014, p. 5). Considerando a telenovela como parte do sistema publicitário, portanto integrante de um contexto da midiatização do consumo, é possível argumentar que, entre os sentidos por ela produzidos, observam-se aqueles relacionados constitutivamente a práticas de consumo, ao conhecimento e aos usos de determinados bens de consumo e bens culturais.

\section{Gosto e valores de classe}

O gosto é tratado neste texto em sua perspectiva social e simbólica, como consideram Bourdieu (2008) e Fiorin (1997). O gosto, na visão dos teóricos, não é uma propriedade natural dos seres humanos, e sim uma faculdade moldada pelo contexto sociocultural, repleta de significações que se vinculam às identidades dos seres sociais e aos objetos aos quais se refere.

Para Bourdieu (1983), o gosto é formado de acordo com o acesso que as diferentes classes sociais têm a capitais culturais. Essas distinções formam estilos de vida variados, nos quais os gostos se configuram e são manifestados por disposições corporais, comportamentos e bens de consumo. Estes últimos vão dos mais básicos, como alimentos e vestimentas, aos mais complexos, como o consumo cultural de obras de arte. Porém, apesar das desigualdades, explica Bourdieu, existe uma ideologia do gosto natural ditado pela classe dominante, que dissimula o âmbito social que condiciona os estilos de vida materiais.

As diferenças sociais mais fundamentais conseguiriam, sem dúvida, exprimir-se através de um aparelho simbólico reduzido a quatro ou cinco 
elementos, tais como Pernod, vinho espumoso, água mineral, Bourdeaux, champanhe, uísque, mais ou menos tão completamente quanto através de sistemas expressivos aparentemente mais complexos e refinados, como os que os universos da música ou da pintura oferecem à preocupação de distinção (BOURDIEU, 1983, p. 84).

Para Bourdieu (2008, p. 97), "o princípio unificador e gerador" de tais práticas poder ser encontrado no "habitus de classe, como forma incorporada da condição de classe e dos condicionamentos que ela impõe". Ainda de acordo com Bourdieu (2008), o gosto das classes populares estaria relacionado a uma necessidade mais imediata, corporal, enquanto as classes altas estariam dissociadas de tal urgência. No que diz repeito à arte, por exemplo, o sociólogo explica que o gosto popular enxerga a estética por ela mesma, dissociada de uma função, de um conteúdo claro, diferente da estética das classes altas que tiveram maior contato com o capital cultural considerado legítimo. A tendência da classe popular é associar a arte com a própria vida, sem uma distinção entre forma e conteúdo. "Seja no teatro ou no cinema, o público popular diverte-se com as intrigas orientadas, do ponto de vista lógico e cronológico, para um happy end [...]" (BOURDIEU, 2008, p. 35).

Fiorin (1997), em discussão baseada na perspectiva de Bourdieu, acrescenta ao tema um ponto de vista semiótico. De acordo com o autor, o gosto é como uma aptidão que torna distinto o indistinto " [...] o que significa que ele existe pela relação, na e pela diferença” (FIORIN, 1997, p. 15). Segundo o teórico, o sujeito adquire uma definição relacional com o objeto, chamada de existência modal, caracterizada, por exemplo, por um querer ser conjunto com o objeto e um não querer ser em relação ao gosto de outros.

Fiorin afirma que, em sua forma mais abstrata, o gosto é o estabelecimento da descontinuidade na continuidade, da diferença na indiferenciação. "O que foi distinguido é sobredeterminado pela euforia, enquanto o contínuo, o indiferenciado é visto como disfórico" (FIORIN, 1997, p. 15). A categoria semântica de base seria a exclusividade versus a inclusividade. 
Nessa linha de raciocínio, Fiorin também ressalta a questão ideológica e social relacionada ao gosto, em consonância com o que Bourdieu (2008) aborda a respeito do gosto legítimo.

O gosto dominante transforma-se em bom gosto e, portanto, serve de norma para o futuro, tornando-se um dever fazer. Assim, se o gosto no sentido 1 (preferência) é da ordem do querer fazer, o gosto no sentido 2 (aptidão para discernir belezas e defeitos nos produtos do espírito) é do domínio do dever fazer. Quem não se conforma a esse dever fazer é sancionado negativamente: é brega. Gosta-se do que é preciso gostar (FIORIN, 1997, p. 22).

Em outras palavras, a produção de sentidos relacionada ao bom e ao mau gosto na telenovela traduz-se por meio do reflexo e da refração relacionados não apenas aos objetos presentes no espaço da enunciação fílmica, mas também principalmente por meio dos discursos que os tornam ideologicamente perceptíveis como prenhes de valor no contexto da enunciação. Cabe lembrar, nesse mesmo sentido, a discussão de Bakhtin e Volochinov (2002, p. 32) acerca da avaliação ideológica constituinte do signo, pois “um signo não existe apenas como parte de uma realidade; ele também reflete e refrata uma outra. Ele pode distorcer essa realidade, ser-lhe fiel, ou apreendê-la de um ponto de vista específico etc. Todo signo está sujeito aos critérios de avaliação ideológica [...]".

Nesse sentido, podemos tomar as palavras de Appadurai (2008, p. 56), que propõe, ao tratar dos bens de luxo, que se considerem "os bens de luxo não exatamente em contraste com as necessidades (um contraste cheio de problemas), mas como bens cujo uso principal é retórico e social, bens que são simplesmente símbolos materializados".

No caso específico do estudo a que se propõe este artigo, cabe ainda lembrar a afirmação de Bourdieu (2008, p. 54) quanto à disposição estética,

que tende a deixar de lado a natureza e a função do objeto representado, além de excluir qualquer reação "ingênua", ou seja, horror diante do horrível, desejo diante do desejável, reverência piedosa diante do sagrado, assim como todas as respostas puramente éticas para levar em 
consideração apenas o modo de representação, o estilo percebido e apreciado pela comparação com outros estilos - é uma dimensão da relação global com o mundo e com os outros, de um estilo de vida, em que se exprimem sob uma forma incognoscível, os efeitos de condições particulares de existência [...] (BOURDIEU, 2008, p. 54).

Levando em conta a proposta deste trabalho, cabe ainda elucidar que a cena da enunciação (MAINGUENEAU, 2008), considerada no corpus, configura-se como o espaço no qual se instauram os sujeitos da enunciação por meio da discursivização, ou seja, “o mecanismo criador da pessoa, do espaço e do tempo da enunciação." (FIORIN, 2005, p. 43). Ao tomar a palavra, o indivíduo instaura não apenas a si mesmo como enunciador, mas também o espaço (por meio de advérbios) e o tempo (por meio dos tempos verbais) do ato enunciativo. Recorrendo a Greimas (apud FIORIN, 2005, p. 42), podemos dizer que o sujeito, no ato da enunciação, "constrói o mundo enquanto objeto ao mesmo tempo que se constrói a si mesmo".

Ainda em relação à enunciação, destacamos que, para Bakhtin e Volochinov (2002), a apropriação da língua por parte do sujeito ocorre por meio da compreensão semiótica, que é socialmente constituída, já que todo enunciado se constrói direcionado e condicionado por duas forças que agem sobre o indivíduo, a individual e a social. Assim, para Bakhtin e Volochinov, “a enunciação individual não pode ser dissociada do todo social e histórico no qual ela se insere e com o qual dialoga de forma constitutiva e interpretativa" (MUNGIOLI, 2009, p. 592). É por meio da enunciação, ou seja, da concretude do discurso que se pode observar que "classes sociais diferentes servem-se de uma só e mesma língua. Consequentemente, em todo signo ideológico confrontam-se índices de valor contraditórios. O signo se torna a arena onde se desenvolve a luta de classes" (BAKHTIN e VOLOCHINOV, 2002, p. 46).

Landowski (1997) discute a ideia de gosto não apenas entre sujeito e objeto, mas também entre sujeito e sujeito. Para ele, há um gosto objetal e um subjetal. Neste último encontra-se o gosto por agradar alguém. O agrado pode ser concretizado em virtude dos gostos objetais de quem se 
deseja agradar, pois esses objetos fazem parte da composição da identidade do sujeito, que acaba se tornando também o objeto do gosto do outro.

Assim, tem-se o pertencimento a grupos de classe social, como demonstra Bourdieu (2008), por acesso a capitais culturais distintos que configuram comportamentos, estilos de vida e gostos diversos. Nesse sentido, os objetos "falam" desse pertencimento a um grupo.

Ainda, o gosto referente a esses objetos pode passar por mudanças para que o pertencimento ao grupo de referência seja mantido. Landowski (1997) explica que certa inconstância de gosto, sobretudo para seguir determinada moda, é comum e se configura no que ele chama de parecer e ser, ou programa principal e subjacente. O programa subjacente comporta as mudanças de preferências e escolhas para que o indivíduo continue coerente àquilo que ele deseja ser, ao programa principal, no qual se encontra seu grupo de pertencimento.

\section{Império, semijoias e gosto}

A discussão empreendida neste trabalho com relação à construção do sentido de "bom" e "mau" gosto na telenovela Império estrutura-se em torno dos discursos das personagens Maria Clara - e alguns de seus familiares - e Cristina em cena que foi ao ar em 31/12/2014. A cena foi transmitida dias após a ação de merchandising mais destacada da Rommanel na telenovela, a de um coquetel de lançamento da coleção desenhada por Maria Clara. Trata-se de uma linha de semijoias que foi lançada no mercado real com o nome coleção Rommanel Império.

Em outras ações da marca, personagens aparecem utilizando anéis, brincos e colares Rommanel, como Maria Clara, Amanda (Adriana Birolli), Juliane (Cris Vianna), Érika (Letícia Birkheur), Danielle (Maria Ribeiro), Du (Josie Pessoa) e Bianca (Juliana Boller). É importante destacar que essas personagens fazem parte tanto do núcleo rico quanto do núcleo popular da trama.

Na cena a seguir transcrita, Cristina, moça de origem pobre e que, no passado, trabalhara em um camelódromo, está no comando da empresa, 
nomeada por seu pai - que simula a própria morte. Cristina não é aceita pela esposa e pelos herdeiros legítimos do comendador, que não desejam dividir a herança com a filha bastarda, que aparece em suas vidas depois de adulta.

Para entrar nesse novo universo familiar, Cristina passa por um processo de mudança de estilo para agradar a outros sujeitos e para se adequar a seu novo lugar social: executiva de uma importante empresa de pedras preciosas e joias. Fato que não deixa de ser notado por Maria Marta, conforme veremos no trecho selecionado para análise. Nesse trecho, também Maria Clara e José Pedro se referem aos clientes fidelizados, à classe $\mathrm{A}$, ao nicho de mercado. Ou seja, círculos aos quais eles pertencem.

Pois, afinal de contas, quer o grupo de referência se identifique com certo meio profissional, ou alhures, com alguma camada social particular, quer se defina, como também regra comum, em termos de afinidade de geração, que recurso os seus respectivos membros têm para manifestar de modo simples, claro e contínuo, sua preferência aos ditos grupos, a não ser a adoção de condutas que mostrem, enfaticamente se for preciso, que os princípios de avaliação que utilizam para definir sua posição pessoal sobre os assuntos mais variados, a cada momento coincidem com os que "todo mundo" julga os mais adequados na coletividade considerada? (LANDOWSKI, 1997, p. 106).

Na ocasião, a empresa Império passa por uma grande crise financeira e a solução encontrada por Cristina envolve uma mudança em relação aos produtos produzidos e comercializados pela joalheria, o que consequentemente significará mudança na clientela da marca. Sua proposta é que a joalheria passe a produzir e comercializar anéis de formatura e joias para homens. Maria Clara e seu irmão José Pedro (Caio Blat) - os dois filhos mais atuantes na empresa, que veem a presença de Cristina no comando da Império como uma usurpação de seus direitos como filhos legítimos do Comendador - indignam-se com a proposta, pois esses produtos fogem da proposta da empresa. Os anéis de formatura, especialmente, são tidos como muito populares e, por isso, não estariam 
à altura do prestígio conquistado pela empresa ao longo dos anos, ou seja, de sua imagem e identidade de marca. Vejamos a transcrição do diálogo, do qual extraímos alguns excertos, e que se estendeu em duas cenas diferentes de um mesmo capítulo.

José Pedro: Anéis de formatura? Você acha que vai salvar a Império com essa ideia estapafúrdia?

Maria Clara: Eu disse para ela que anel de formatura é uma joia que tá inteiramente fora de moda.

Maria Marta: Gente, mas como se ela entendesse disso, meu Deus do céu.

Cristina: Vocês têm toda a razão, eu não sou nenhuma expert em moda. Mas eu sei que o que esteve em moda em um determinado momento retorna. Foi assim com a calça boca de sino, com a blusa xadrez, com o mocassim.

Maria Clara: Aquele topzinho que você usava no cabelo....

Risos.

Maria Marta: Ah, desculpa, aquele topzinho que lembrava a viúva Porcina...

Cristina: Podem debochar à vontade...

José Pedro: Não é deboche, Cristina. É que simplesmente você não tem noção. Você é capaz de confundir uma peça de roupa vagabunda com uma joia de alto luxo...

Cristina: Só que o alto luxo não está pagando a conta, José Pedro. Você sabe disso melhor do que elas. Com tanta gente se formando a cada semestre nesse país, cada vez mais... eu mesma me formo agora em seguida.

Maria Clara: Então, você está legislando em causa própria. Não, por isso não. Eu posso indicar uma lojinha muito boa onde você pode comprar um anel.

Cristina: Não é isso, Maria Clara. Eu tô pensando no público, e um público crescente. $\mathrm{O}$ anel de formatura pode voltar a ser um objeto de 
desejo. Imagina a Império fabricando uma coleção para esses jovens, uma coleção bonita, elaborada, com uma bela campanha publicitária.

Maria Marta: Em resumo, ela quer achinesar a Império.

Maria Clara: E daí para confecção de miçanga e pedraria de carnaval, ó, pulo.

Maria Clara: Eu disse que eu discordo da sua proposta, porque pra te dizer a verdade eu achei ela ridícula. Então, Cristina, não conte comigo pra desenhar porcaria de anel de formatura nenhum e nem joia pra marmanjo. Eu tô fora.

Cristina: Você vai se negar a fazer isso? É isso mesmo? Você tem certeza?

Maria Clara: Com toda a certeza do mundo. Eu estudei por anos pra fazer joias femininas, encantadoras, eternas. Foi nisso que eu me especializei. Eu não posso de repente agora começar a desenhar miçanga...

Maria Marta interfere para dizer que a ideia da Cristina é sensata, porque eles estão imersos em uma crise.

José Pedro: Eu não tô acreditando que você poderia concordar com a mudança de perfil da Império. Mãe, a Império tem uma marca. A Império tem um nicho de mercado estabelecido, uma clientela fidelizada.

Cristina: E tudo isso não impediu que a gente caísse na bancarrota. Clientela fiel, nicho estagnado, mas que não compra constantemente porque o custo é alto.

Maria Clara: Só não pode esquecer de uma coisa, a crise não se estabeleceu porque as joias não fazem sucesso.

Cristina: O que vai ajudar a gente agora é lançar produtos mais acessíveis, atrativos e de rápido consumo.

Maria Clara: Gente, desenhar anel de formatura e pingente pra homem não faz meu estilo.

Cristina: Maria Clara, você está sendo egoísta e nada razoável.

Maria Clara: Não é minha intenção ser. Cristina, não é porque meu pai te deu poderes que eu vou dizer amém para as suas ideias típicas de 
quem não valoriza o nosso lugar no mercado. O nosso público é e sempre foi o A e não a classe $\mathrm{C}$. Se eu disser sim pra você agora, amanhã você vai ter a grande ideia de colocar a minha coleção inteira pra vender no camelódromo.

Com base nos enunciados acima, discutiremos alguns elementos levando em consideração que as falas das personagens se constituem por meio de signos ideológicos que comportam índices de valor contraditórios. Nesse mesmo sentido, conforme adverte Barros (2011), é no discurso que se encontram as questões ideológicas do texto.

O exame interno do texto não é suficiente, no entanto, para determinar os valores que o discurso veicula. Para tanto, é preciso inserir o texto no contexto de uma ou mais formações ideológicas que lhe atribuem, no fim das contas, o sentido (BARROS, 2011, p. 83).

Na cena em análise, temos uma oposição de gostos marcada pelo pertencimento social de Cristina por um lado e Maria Clara, Maria Marta e José Pedro de outro. Primeiramente, é válido realçar a "mudança de gosto" de Cristina quando esta começa a trabalhar na empresa Império. No início da trama, quando trabalhava no camelódromo, a moça se vestia com calça jeans, blusa de alça e o "topzinho" (mencionado no diálogo) amarrado na cabeça. Ao entrar na empresa, Cristina começa a se vestir segundo um padrão identificado como o de uma executiva, usa os cabelos soltos, bem-arrumados e maquiagem. Ou seja, ela entra em conformidade com as regras de um novo ambiente social para ser bem-vista e aceita, o que corrobora a afirmação de Landowkski (1997) acerca das manifestações do gosto incidindo sobre os padrões de conduta e comportamento para as operações de inserção e pertencimento a um grupo.

Desse modo, retomando a ideia relacional de Fiorin (1997) ao abordar a forma mais abstrata do gosto através da categoria semântica de base exclusividade (descontínuo e distinguido - eufórico) e inclusividade (contínuo e indiferenciado - disfórico), é preciso pontuar que a exclusividade também é inclusão, no sentido do pertencimento a grupos 
sociais, e a inclusividade também é exclusiva, já que todos os gostos se distinguem de um "outro".

No caso aqui proposto, é possível sugerir que, na cena analisada, há a oposição fundamental entre gosto de luxo e gosto popular. O primeiro se identifica com o eufórico e o segundo, com o disfórico. O quadro abaixo demonstra as oposições constitutivas do discurso das personagens na cena transcrita.

\begin{tabular}{ll}
\hline $\begin{array}{l}\text { Gosto de luxo (Maria Clara, Maria Marta } \\
\text { e José Pedro) }\end{array}$ & Gosto popular (Cristina) \\
\hline Eterno & Achinesar \\
\hline Luxo & Fora de moda \\
\hline Classe A & Classe C \\
\hline Público fidelizado & Camelódromo \\
\hline Moda & Fora de moda \\
\hline Para poucos & Achinesar \\
\hline Inacessível & Acessível \\
\hline Tradicional & Formatura \\
\hline
\end{tabular}

Quadro 1 - Categorias semânticas de base Fonte: Autoria própria.

Em primeiro lugar, no caso da palavra "formatura" na coluna da direita, é importante explicitar seu vínculo com o popular no texto analisado e discórdia com a noção de tradicional no que diz respeito à concepção de posicionamento de classe social, pois, na atualidade, a ascensão educacional já não se reserva a poucos e, portanto, não se configura por si só como uma "expressão distintiva" e não pode expressar autonomamente “afirmação prática de uma diferença inevitável” (BOURDIEU, 2008, p. 56). Correlacionado inevitavelmente ao prestígio/valor social do próprio diploma universitário ${ }^{6}$ em uma sociedade na qual se difunde a ideia de

\footnotetext{
${ }^{6}$ A trama reforça que a personagem conseguiu concluir o ensino superior com muito esforço, fazendo trabalhos extras, como vender bolo de chocolate, para pagar os estudos. É importante destacar o merchandising da instituição UNIESP na telenovela.
} 
que mesmo os mais pobres ${ }^{7}$ podem ter acesso ao ensino universitário, o anel de formatura também simboliza uma ascensão conquistada tardiamente pelos menos abastados; portanto, a expressão "fora de moda" usada por Maria Clara desvela o sentimento de classe desta última em relação não apenas a um objeto, mas também às pessoas (e, por conseguinte, à classe social) e a todas as práticas sociais que ainda valorizam anacronicamente um objeto incapaz, a seu ver, de simbolizar status e diferenciação.

Destaca-se também que, no quadro anterior, na coluna da direita, do gosto popular, há alusão aos valores que se vinculam à ideia de série, do feito em grande escala a preço baixo, explícitas nas palavras "achinesar" e "camelódromo". E na coluna da esquerda, do gosto de luxo, estão os valores do modelo, do original.

Conforme explica Baudrillard (2006), os produtos (compreendemos também como cultura e educação) que chegam às classes média e baixa já não são os mesmos a que a elite tem acesso. Eles são diluídos. As pessoas de classe média e baixa consomem os resquícios da alta burguesia, produtos que ela já categorizou como "fora de moda". O modelo é destinado aos privilegiados e a série (kitsch) é para o resto, explica Baudrillard.

Porém, a oposição entre modelo e série revela, hoje em dia, contradições em seu interior, bem como no discurso do texto exposto. Pois, como explica Lipovestsky (2009), o estilo original já não é mais privilégio do luxo, “[...] todos os produtos são doravante repensados tendo em vista uma aparência sedutora, a oposição modelo/série turvou-se, perdeu seu caráter hierárquico ostentatório" (LIPOVETSKY, 2009, p. 189). Não quer dizer que os extremos desapareceram, aclara o autor, mas não exibem mais uma diferença incomparável.

Desse modo, o discurso de Maria Clara, Maria Marta e José Pedro é uma tentativa de reafirmar uma posição de exclusividade, luxo e diferenciação já ambígua em nossa atual sociedade de consumo. Há

${ }^{7}$ Citamos como exemplo de política pública voltada para a democratização do acesso ao ensino superior o programa Universidade para Todos (Prouni). Disponível em: http://siteprouni.mec.gov. br/o_prouni.php. Acesso em: 1 maio 2015. 
contradição também nas palavras "tradicional" e "eterno" versus "moda", pois a moda por si só já expõe a lógica da efemeridade (LIPOVETSKY, 2009).

Do mesmo modo, o fato de Maria Clara ser a designer da nova coleção para a Rommanel destoa dos valores que a família tenta transmitir nessa cena. Semijoias não são produtos considerados de alto luxo a priori. A Rommanel fabrica peças folheadas a ouro e joias em aço, que não são destinadas ao público A, necessariamente, nem são tão inacessíveis em termos de valor.

Nesse caso, argumenta-se que a marca Rommanel vincula-se a esses valores do gosto de luxo em um sentido aspiracional. Ou seja, as clientes da marca aspiram a determinados padrões e status de luxo e classe que não necessariamente fazem parte dos produtos em termos mais concretos, mas da imagem pretendida pela marca. Como destacado anteriormente, não são apenas as personagens do núcleo rico de Império que usaram, ao longo da telenovela, as peças da Rommanel, mas também as do núcleo popular.

Além disso, deve-se notar que, apesar do discurso de Cristina não estar alinhado ao que se pode identificar como o discurso da marca em termos de gosto refinado "para poucos", seu enunciado desempenha papel importante na produção de sentidos de valorização do gosto popular e da possibilidade de ascensão, materializados pela formatura e pelo anel, que aparecem como símbolos de transformação da moça, formada em administração em uma faculdade de pouco prestígio - como seu irmão José Pedro costuma enfatizar - depois de muito batalhar. $\mathrm{O}$ anel de formatura, que pode ser interpretado como porta de entrada da classe C ao mundo de luxo da Império e como um símbolo de transformação social pela via da educação, ganha, dessa forma, materialidade como capital simbólico e, em certa medida, como "objeto de culto" (BOURDIEU, 2008, p. 73). A marca Rommanel, ao vincular-se à trama, passa a compor o interdiscurso do mercado, no qual se desvela a aspiração do popular ao luxuoso, buscando materializar-se como algo diferenciado, 
ou seja, aquilo que é, ao mesmo tempo, para poucos, está na moda e simboliza a legitimidade da aspiração à mudança de status social.

O discurso sobre o gosto de classe na cena escolhida, como vimos, desqualifica o gosto popular, coloca-o como fora de moda e reafirma o gosto da classe alta como legítimo e universal. Pois Cristina afirma não entender nada de moda, e sim da empresa comercial que está falindo e precisa de lucro rápido. Assim, seu discurso não se afirma sobre os mesmos pilares de seus interlocutores, revelando, de certa forma, o seu não pertencimento ao universo deles em termos de valores e consumo - portanto, à classe social destes últimos. Seu discurso pretende se articular sobre a objetividade do balanço da empresa que se encontra arruinada. Nesse sentido, seus argumentos soam, do ponto de vista do gosto, como reafirmadores da fala de seus irmãos e de Maria Marta. Ao contrário dela, no trecho analisado, Maria Clara, José Pedro e Maria Marta, embora sejam apresentados como arrogantes no decorrer da narrativa da telenovela, não têm seus gostos negados, mas reafirmados como valores que identificam a imagem da empresa Império. Apenas Maria Marta mostra-se mais atenta aos argumentos de Cristina, fazendo isso apenas por levá-los em consideração do ponto de vista financeiro.

O bom gosto legítimo continua sendo o considerado de luxo, o da classe A. Mas este é penetrado por novas lógicas do popular, da acessibilidade, da semijoia e do anel de formatura. E, de certa forma, pela trajetória de mulher batalhadora que caracteriza a personagem Cristina, que estudou e desenvolveu sua habilidade comercial por esforço próprio e com uma força de vontade excepcional, conforme se afirma constantemente durante a telenovela, ressaltando sua "trajetória individual" (BOURDIEU, 2008, p. 104). Entrevê-se, assim, o discurso do mercado, da publicidade, do consumo e do individualismo como característica da ascensão social. Em consonância com o que afirma Lipovestky (2009, p. 184) sobre a sociedade do consumo: "a sociedade centrada na expansão das necessidades é, antes de tudo, aquela que reordena a produção e o consumo de massa sob a lei da obsolescência, da sedução e da diversificação, aquela que faz passar o econômico para a órbita da forma moda". 
O discurso da cena analisada, desse modo, reafirma a individualidade e o subjetivismo voltado à satisfação pessoal nos desejos de consumo, o que demonstra a conexão entre a lógica do capital e as representações midiáticas sobre consumo e classe social, aspecto esse que já havia sido sinalizado por Campbell (2001) em sua obra A ética romântica e o espírito do consumismo moderno.

\section{Considerações finais}

O artigo deteve-se no estudo de aspectos da produção de sentido do gosto de classe por meio de discursos da telenovela Império. Identificamos, ao longo da análise dos discursos de uma cena, elementos da enunciação que compõem a trama discursiva por meio da qual se torna possível observar a construção social do signo ideológico (BAKHTIN e VOLOCHINOV, 2002) e sua refração em relação às classes sociais no que diz respeito ao gosto (tanto o "bom" quanto o "mau" gosto). O estudo da enunciação das personagens sobre o objeto "anel de formatura" levou-nos a observar a oposição entre gosto de luxo (o bom gosto) e gosto popular (o mau gosto). A telenovela reafirmou em seu discurso o gosto de luxo da classe dominante como o legítimo e universal, embora este estivesse mesclado com valores populares. Trata-se do discurso do mercado, de ascensão e consumo individual presente em nossa sociedade. Esse é o contexto no qual o discurso midiático e os gostos estão ancorados na medida em que ocorre a midiatização do consumo estabelecida pela construção de vínculos de sentido que tornam possíveis os hábitos e atitudes de consumo entre as expressões da marca/produtos/serviços e seus consumidores.

Dessa forma, a análise do discurso, tendo como base a enunciação e suas possibilidades interdiscursivas, mostra-se frutífera para um estudo que busca a conjunção entre os aspectos socioideológicos e os textos midiáticos. Estes últimos, enquanto parte de uma dada realidade histórico-social, podem reproduzir discursos hegemônicos vigentes, mas também os transformam na medida em que as mídias e seus produtos culturais - mais especificamente aqui a telenovela - participam, ao 
mesmo tempo, da dinâmica do cotidiano, na qual os signos são ressignificados constantemente. Tais marcas de reprodução e transformação são perceptíveis pela composição verbo-visual da enunciação discursiva analisada neste trabalho.

\section{Referências}

ALMEIDA, H. B. de. Telenovela, Consumo e Gênero. Bauru: EDUSP, 2003.

APPADURAI, A. A vida social das coisas: as mercadorias sob uma perspectiva cultural. Niterói: Universidade Federal Fluminense, 2008.

BACCEGA, M. A.; OROFINO, M. I. R. (Orgs.). Consumindo e Vivendo a vida - telenovela, consumo e seus discursos. São Paulo: Intermeios, 2013. BAKHTIN, M; VOLOCHINOV, V. N. Marxismo e Filosofia da Linguagem. São Paulo: Hucitec, 2002. BARROS, D. L. P. de. Teoria Semiótica do Texto. São Paulo: Ática, 2011.

BAUDRILLARD, J. O sistema dos objetos. São Paulo: Perspectiva, 2006.

BOURDIEU, P. A distinção: crítica social do julgamento. Porto Alegre: Zouk, 2008.

Gostos de classe e estilos de vida. In: ORTIZ, R. (Org.). Pierre Bourdieu: Sociologia. São Paulo: Ática, 1983. p. 82-121.

CAMPBELL, C. A ética romântica e o espírito do consumismo moderno. Rio de Janeiro: Rocco, 2001.

CANCLINI, N. G. Consumidores e cidadãos: conflitos multiculturais da globalização. Rio de Janeiro: UFRJ, 2008.

CERTEAU, M. A invenção do cotidiano. 1. Artes de fazer. Petrópolis: Vozes, 2007.

COULDRY, N.; HEPP, A. Conceptualizing mediatization: contexts, traditions, arguments. Communication Theory, v. 23, n. 3, p. 191-201, ago.-dez. 2013.

FIORIN, J. L. As astúcias da enunciação: as categorias de pessoa, espaço e tempo. São Paulo: Ática, 2005.

De gustibus non est disputandum? Para uma definição da semiótica do gosto. In: LANDOWSKI, E.; FIORIN, J. L. (Orgs.). O gosto da gente, o gosto das coisas. São Paulo: EDUC, 1997.

HALL, S. Codificação/Decodificação. In: Da diáspora: identidades e mediações culturais. Belo Horizonte: UFMG, 2003.

HAMBURGER, E. Diluindo fronteiras: a televisão e as novelas no cotidiano. In: SCHWARCZ, L. M. (Org.). História da Vida Privada no Brasil. São Paulo: Companhia das Letras, 1998.

IMPÉRIO. Roteiro: Aguinaldo Silva. Direção-geral: Rogério Gomes. Rio de Janeiro: Rede Globo de Televisão, 2014. 
LANDOWSKI, E. Gosto se discute. In: ; FIORIN, J. L. (Orgs.). O gosto da gente, o gosto das coisas. São Paulo: EDUC, 1997.

LIPOVETSKY, G. O império do efêmero. A moda e seu destino nas sociedades modernas. São Paulo: Companhia das Letras, 2009.

LOPES, M. I. V. Telenovela como recurso comunicativo. Matrizes, v. 3, n. 1 p. 21-48, ago.-dez. 2009.

.; BORELLI, S.; RESENDE, V. Vivendo com a Telenovela: mediações, recepção, teleficcionalidade. São Paulo: Summus, 2002.

MAINGUENEAU, D. Cenas da enunciação. São Paulo: Parábola Editorial, 2008.

MUNGIOLI, M. C. P. Minisséries Brasileiras: um lugar de memória e (re)escrita da nação. In: CASTRO, G. G. S.; BACCEGA, M. A. (Orgs.). Comunicação e consumo nas culturas locais e globais. São Paulo: ESPM, 2009.

OROFINO, M. I. R. Contribuições para o debate sobre comunicação e educação: crianças, telenovela, tecnologias. In: BACCEGA, M. A.; OROFINO, M. I. R. Consumindo e Vivendo a vida - telenovela, consumo e seus discursos. São Paulo: Intermeios, 2013.

SODRÉ, M. A ciência do comum: notas para o método comunicacional. Petrópolis: Vozes, 2014.

TONDATO, M. P. A recepção da ficção televisiva como espaço de significação e constituição de identidades: nos limites entre o real e o ficcional. Revista Comunicação \& Inovação, v. 12, n. 23, p. 11-20, 2011.

Representações ficcionais à mesa: espaços e estilos de alimentação como diferenciação social. In: CONGRESSO BRASILEIRO DE CIÊNCIAS DA COMUNICAÇÃO - INTERCOM, 35, 2012, Fortaleza. Anais... Fortaleza: Universidade de Fortaleza, 2012. p. 15.

TONDATO, M. P. Uma perspectiva teórica sobre consumo e cidadania na contemporaneidade. Conexiones. Revista Iberoamericana de Comunicación, v. 2, n. 2, p. 5-18, 2010. .; BACCEGA, M. A. A Telenovela nas Relações de Comunicação e Consumo: Diálogos Brasil e Portugal. Jundiaí: Paco Editorial, 2013.

TRANQUILIN-SILVA, J. F. O tecer das emoções femininas em Vila Pouca do Campo: a telenovela Senhora do Destino. In: CUNHA, I. F. (Org.). A TV das Mulheres: ensaio sobre a recepção. 1. ed. Lisboa: BonD, 2006. p. 109-130.

TRINDADE, E.; PEREZ, C. Dimensões do consumo midiatizado. In: CONGRESSO MUNDIAL DE COMUNICAÇÃO IBERO-AMERICANA - CONFIBERCOM, 2, 2014, Braga. Anais... Braga: Universidade do Minho, 2014. p. 1-9. 
96 A CONSTRUÇÃo Discursiva do GOSTO DE ClaSSE NA TELENOVELA

\section{Sobre as autoras}

Maria Cristina Palma Mungioli - Professora da Escola de Comunicações e Artes - ECA/USP. Doutora em Ciências da Comunicação pela Escola de Comunicações e Artes - USP; realizou pós-doutorado na Université Sorbonne Nouvelle (Paris 3) com bolsa FAPESP. Tem trabalhado com os seguintes temas: comunicação, linguagem televisual, telenovelas e identidades, linguagem e cognição, cultura narrativa e narrativa, ensino e aprendizagem de língua materna.

Rosana Mauro - Doutoranda em Ciências da Comunicação pela ECA/USP. Mestre em Ciências da Comunicação pela ECA/USP (2014). Participa do Grupo de Pesquisa Jovens e Consumo Midiático da Universidade Federal do Rio Grande do Sul (UFRGS). Especialista em Comunicação Organizacional - Relações Públicas pela Faculdade Cásper Líbero (2007).

Data de submissão: 01/06/2016

Data de aceite: 23/11/2016 